\title{
Yüz İfadelerindeki Duygular: Derleme Çalışması
}

\author{
DOI: 10.26466/opus.514880 \\ *
}

\section{$\underline{\text { Ahmet Metin }}^{*}$}

* Arş. Gör., Erciyes Üniversitesi, Eğitim Fakültesi, Kayseri / Türkiye

E-Posta: ametin@erciyes.edu.tr

ORCID: $\underline{0000-0001-6519-2523}$

\section{Öz}

Duygu, özellikle son dönemlerde psikoloji biliminin odaklandığı konulardan birisi olmuştur. Duygu ilk olarak yüz bölgesinde ortaya çımaktadır dolayısıyla yüz ifadeleri duyguların tanınmasına aracılık etmektedir. Bu çalışmanın amacı ulusal alanyazında sınırl olan yüz ifadelerindeki duygular konusunun ele alınmasıdır. Bu çerçevede uluslararası çalışmalar kapsamlı bir şekilde gözden geçirilmiştir. İnsan yaşamında önemli bir yeri olan duygular ve yüz ifadeleri 1824 yllından beri alanyazında yer edinmektedir. Yapılan araştırmalar sonucunda yüz ifadelerindeki duyguların tüm insanlar tarafindan benzer şekilde görüldü̈̆̈̈̈ anlaşılmıştır. Dolayısıyla yüz ifadelerindeki duyguların evrenselliğine ilişkin yapılan araştırmalar incelenmiştir. Öte yandan yüz ifadelerindeki duyguların farklı kültürlerden nasıl etkilendiği de ele alınmıştır. Yüz ifadelerinin tanınmasını etkileyen çeoresel faktörler ise bir başka ele alınan konu olmuştur. Hayatın hemen hemen her alanında olan duygu ifadelerinin doğası, bu makalede ayrıntılı olarak tartışılmıştır. Ayrıca yüz ifadelerine ilişkin yapılan araştırmaların yöntemsel farklllıkları sunulmuştur. Bu derleme çalışmasılyla alanyazında önemli bir boşluğun doldurulacağı düşünülmektedir. Bu alana ilişkin çalışma yapacak araştırmacılara da ışık tutacağı düşünülmektedir.

Anahtar Kelimeler: Duygular, yüz ifadeleri, evrensellik. 


\title{
Emotions in Facial Expression: Review
}

\begin{abstract}
Emotion, especially in recent years, has been one of the subjects focused on the science of psychology. Emotion first appears in the facial region, therefore facial expressions mediate the recognition of emotions. The purpose of this study is reviewed the issue of emotions in facial expressions limited to national literature. Within this framework, international studies have been comprehensively reviewed. Emotions and facial expressions have an important in human life since 1824. As a result of the researches, it was understood that the emotions in facial expressions were similar to all people. Hence, researches on the universality of emotions in facial expressions were examined. On the other hand, the effects of facial expressions on different cultures were also examined. Environmental factors influencing the recognition of facial expressions have been the subject of another. The nature of emotion expressions in almost every aspect of life has been discussed in detail in this paper. In addition to methodological differences of facial expressions are presented. It is thought that this review will fill an important gap in the literature. It is thought that it will shed light on the researchers who will work on this field.
\end{abstract}

Keywords: Emotions, facial expressions, universality. 


\section{Giriş}

Yüzyıllardır insan doğası anlaşılmaya çalışılmaktadır. 1800'lü yılların sonlarında kurulan ilk psikoloji laboratuvarı ile insan doğası sistematik yöntemlerle araştırılmaya başlanmıştır (Harper, 1950). Psikoloji üzerine yapılan çalışmaların hız kazanması ise şüphesiz Freud'un $(1912,1920)$ çalışmalarıyla başlamıştır. İnsanlık tarihinden Freud'un çalışmalarına kadar uzanan sürede insanın bilinçdışı tarafı bilinmemekteydi. Freud ile alanyazında bilinçdışı kavramı söz edilmeye başlanmış ve bu kavram üzerine yapılmış ve yapılmakta olan birçok araştırma bulunmaktadır. Ancak bilinçdışı kavramının ölçülememesi bazı kuramcıların eleştirisine sebebiyet vermiştir. Davranışın ölçülmesiyle insan doğasına ilişkin yeni görüşler ortaya atılmıştır (Skinner, 1963). Aynı dönemlerde bilişsel oluşumun kökeni anlaşılmaya çalışılmış ve şema kavramı ileri sürülmüştür (Piaget, 1964). İnsan doğasının hem bilinçli hem de bilinçdışı dahilinde davranışsal ve bilişsel yönlerinin ele alınmasını takiben son dönemlerde duygu boyutunun vurgulanmaya başladığı görülmektedir (Ekman ve Friesen, 1971; Ekman ve Friesen, 1986; Ekman ve Friesen, 2003; Izard, 1977; Izard, 1991; Greenberg, 2006; Greenberg ve Safran, 1989; Gülbetekin, Bayraktar, Özkan, ve Özkan, 2017; Panksepp, 2004; Sloan, 2004; Tatar, Yargıç, Oflaz ve Büyükgök, 2015).

\section{Duygular}

Duygunun insan yaşamında ve güdülenmesinde önemli işlevleri vardır (Matsumoto, Frank ve Hwang, 2013). Örneğin, korku duygusu kişinin yaşamını devam ettirmesine aracılık edebilmekteyken; öfke duygusu ise kendiliğin korunmasını sağlamaktadır (Greenberg, 2011). Duygunun işlevlerinden birisi örnekle açıklanacak olursa, bireyin canına mal olacak bir durumda korku duygusu devreye girebilir ve bireyin kendisini daha güvenilir bir ortamda bulunmasına aracilık edebilir.

Alanyazında duygu kavramının çeşitli tanımlamaları bulunmaktadır. Bir tanıma göre duygu "evrensel paylaşımlara, kültüre ve bireye özgü olaylara verilen ve ayırt edici özellikleri olan otomatik tepkiler"dir (Ekman ve Cordaro, 2011, s.364). Bu tanımı açmak gerekirse, öncelikle duygunun bir otomatik tepki olduğu belirtilmektedir. Burada otomatik tepki 
ifadesiyle duygunun biyolojik kökenini vurgulanmaktadır. Özellikle nöronal süreçlerin saliseler içerisindeki işleyişi, duyguların otomatik yapısını ortaya koymaktadır. Tanım tekrar ele alındığında duygunun üç alana yönelik otomatik tepki olduğu belirtilmektedir: evrensel paylaşımlar, kültür ve bireye özgü olaylar. Evrensel paylaşımlarla ifade edilmek istenen, bizlerin birer insan olarak verdiğimiz ortak tepkilerdir. Örneğin, bir kişinin uçurumun kenarında düşmek üzereyken veya oldukça süratli bir otomobilin gelmesini takiben kişide oluşan tepkiler otomatiktir dolayısıyla da bedenimizde istem dışı değişimler oluşur. Bir başka deyişle, evrensel paylaşımlar, bütün insanların bir durum karşısında verdiği ortak tepkilerdir.

Tanımda belirtilen otomatik tepkilerden ikincisi, kültüre özgü olaylardır. Bi-yopsikososyal bir varlık olarak insanların kültürden etkilenmemesi düşünülemez. Her bireyin etkilendiği kültür ortamı vardır. Ülkemizden örnek verilecek olursa; Ege Bölgesi'ndeki kültür ile Doğu Anadolu Bölgesi'ndeki kültürün, Karadeniz Bölgesi'ndeki kültür ile de Akdeniz Bölgesi'ndeki kültürün birbirlerinden ayrılan yönleri bulunmaktadır. Kültürü etkileyen birçok faktör göz önünde bulundurulduğunda kültüre özgü verilen duygusal tepkiler daha iyi anlaşılabilmektedir.

Belirtilen son tepki ise bireye özgü olaylara verilen otomatik tepkidir.

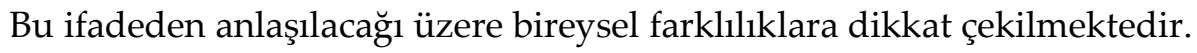
Örneğin, her bireyin kalıtsal özelliklerinden kaynaklanan bazı farklılıkları bulunmaktadır.

Duygu odaklı terapinin kurucusu olan Greenberg ise duyguya farklı açıdan yaklaşmaktadır. Duygunun daha çok sosyal yönlerini vurgulayarak farklı bir beyin olgusu olduğunu ileri sürmektedir. Bu ifade duygunun biyolojik temelinin göz ardı edildiği anlamına gelmemektedir. Nitekim Greenberg duygunun biyolojik ve nörokimyasal temellerinin olduğunu da belirtmektedir (Greenberg, 2015).

Genel olarak toparlanacak olursa, duygunun biyolojik ve nörolojik alt yapısının olduğu ve kendi içinde de bazı farklılıkların olduğu, biyopsikososyal bir varlık olan insan doğasında oluşan otomatik tepkilerdir denilebilir. Tanım göz önünde bulundurulduğunda duygu kavramının temel bir yapı olduğu söylenebilir. Örneğin, belirli bir sürede yaşanan duygudurum ile duygu farklı kavramlardır. Bu çerçevede duygu kavramı bazı 
kavramlarla karıştırılabilmektedir. Goldsmith (1994) duygudurum ve mizaçın duygudan çeşitli yönlerle farklılaştığını ileri sürmektedir. Duygudurum duyguyla kıyaslandığında daha uzun deneyimlenmektedir. Dolayısıyla duygunun daha kısa süreli olduğu vurgulanmaktadır. Mizaç ise kişinin bir özelliğidir ve yaşam boyunca süren bir olgudur. Hem duygudurumda hem de mizaçta duyguyla ilişkilendirilebilecek tepkiler yer almasına rağmen duygu bu iki kavramdan da farklıdır. Bu kavramlara ek olarak his kavramı da bazen duygu ile karıştırılabilmektedir. Tomkins (1962) his kavramını duyguyla ilgili diğer kavramlardan ayırt etmektedir. Bir duygu veya duygulanım oluştuğunda, kişinin bu duruma ilişkin farkındalığına his denilmektedir. Bu açıklamaya bir örnek verilmesi gerekirse, bireyin bir olay karşısında verdiği otomatik tepki korku olsun. Bireyin doğrudan verdiği tepkinin adı duygu (korku) iken; bu duyguyu fark etme durumuna ise his denilmektedir. Dolayısıyla bu kavramlar bir bütün olarak ele alındığında duygu kavramının daha temel bir niteliğinin olduğu söylenebilir.

\section{Duygunun Biyolojik Temeli}

Duyguya ilişkin keşfedilmeyi bekleyen birçok bileşen vardır. Biyolojik temelinin hala açık bir şekilde belirlenememesi duygunun keşfedilmeyi bekleyen yönlerinin olduğunu ispatlamaktadır. Bu çerçevede Aichhorn ve Kronberg (2012) duygunun oluşabilmesi için neokorteks gibi üst düzey beyin yapısına gerek olmadığını belirtmektedirler. Burada MacLean (1990) tarafından ileri sürülen "Üçlü Beyin Modeli" nin açıklanması yerinde olacaktır.

Bu modele göre beyin yapısı kabaca üç bölüme ayrılmaktadır: Sürüngen beyin, paleo memeli ve neo memeli. Bu yapılardan sürüngen beyin, beyin kökünü; paleo memeli limbik sistemi ve neo memeli ise korteksi temsil ettiği ifade edilmektedir (Cozolino, 2014). Açılanan üç beyin kısmindan olan limbik sistemde duygunun oluştuğu ifade edilmektedir. Limbik sistemin hayvanlarda da olduğu ve hayvanların da duyguları yaşadığ1 ve hissettiği (Darwin, 1872/1998) düşünüldüğünde bu katmanın korteks gibi beyin yapısı devreye girmeden duyguların oluştuğu alan olabilmektedir. Hayvanlarda da korteks bulunmasına rağmen insanlardaki 
çok daha gelişmiş bir yapıda olduğundan duyguların yaşanması farklılaşmaktadır. Kısaca söylenecek olursa, duygunun hem hayvan hem de insanlarda deneyimlenmesi limbik sistemden kaynaklandığ 1 ve gelişmiş korteksten ötürü de insanların duyguları sosyal bağlam içerisinde de yaşayabildiği söylenebilir.

Duygunun oluşmasında ve tanınmasında bazı beyin yapıları aktif rol oynamaktadır. Bu yapılardan birisinin ise amigdala olduğu belirtilmektedir (Adolps, Tranel, Damasio ve Damasio, 1995). Bu beyin yapısının başta korku duygusu olmak üzere bazı duygularla (mutluluk, üzüntü, öfke ve nötr ifade) ilişkili olduğu belirtilmektedir (Yang et al., 2002). Belirtilen duygular tetiklendiği esnada amigdalada değişiklik oluşmaktadır. Bu bulgulardan hareketle, amigdalanın hem pozitif hem de negatif duygularla ilişkili olduğu söylenebilir.

Amigdalada herhangi bir değişim oluşturmayan ancak ön insular korteksin aktivasyonunu sağlayan duygu türünün ise tiksinme olduğu belirtilmektedir (Philips et al., 1997). Duygularla ilişkili olduğu düşünülen bir diğer beyin yapsının ise hipokampüs olduğu belirtilmektedir. Hipokampüsün duygusal değerlendirmede aktif rol oynadığı ifade edilmektedir (Aichorn ve Kronberger, 2012). Hafızadan sorumlu önemli bir yap1 olduğu da belirtilen hipokampüsün (Fortin, Agster ve Eichenbaum, 2002; Turner, 1969) duygusal anıların tekrar hatırlanmasını sağladığı söylenebilir. Bunun yanı sıra hafıza ile amigdala arasında bir ilişkiden de söz edilmektedir (Phelps, 2004). Yapılan bir araştırmada duygusal ifadenin uzun süreli belleğin performansını arttırdığı bulgusuna ulaşılmıştır (Diep, 2002). Dolayısıyla da hafıza ile bazı duygularla ilişkili olan amigdalanın duygu üzerindeki işlevlerini desteklemektedir.

Duygu ifadelerinin tanınmasında işlevi olan bazı beyin bölgeleri; oksipitotemporal neokorteks, amigdala, orbitofrontal korteks ve sağ frontoparietal korteks olarak belirtilmektedir (Adolps, 2002). Ayrıca yapılan bir çalışmada sağ beyin hasarı olan katılımcıların sol beyin hasarı olan ve herhangi bir beyin hasarına uğramamış kişilere kıyasla duygu ifadelerini tanımada problem yaşadığı bulgusuna ulaşılmıştır. Bir başka deyişle sağ beyin, yüz ifadelerindeki duyguların tanınmasında önemli bir işlevi vardır.

Duyguların nörolojik yapısına ek olarak fizyolojik değişimlere de sebebiyet verdiği belirtilmektedir. Örneğin Ekman, Levenson ve Friesen (1983) tarafından yapılan araştırmada mutluluk, tiksinme ve şaşkınlık duyguları 
kalp atış hızının düşük olduğu durumlarla ilişkili olduğu bulgusuna ulaşılmıştır. Kalp hızı yüksek olduğunda ise vücut sıcaklığındaki farklılıkların incelenmesinin gerekli olduğu vurgulanmaktadır. Kalp hızı ve vücut sıcaklığı yüksekse öfke duygusu; kalp hızı yüksek, vücut sıcaklığı düşükse üzüntü ve korku duyguları birbirleri arasında ilişkili olduğu belirtilmektedir.

Toparlanacak olursa, duygunun beyinde spesifik bir yerinin olmadığ anlaşılmaktadır. Bunun aksine beyin yapılarının birbirleriyle çoklu etkileşim içerisinde olduğu görülmektedir. Ayrıca bazı duyguların, amigdala gibi beynin belli başlı yapılarını aktive ettiği anlaşılmaktadır. Dolayısıyla duygunun biyolojik temelinde karmaşık etkileşimler söz konusudur.

\section{Duygu ve Biliş}

Alanyazında duygu ve biliş üzerine sayısız tartışmalar bulunmaktadır. Örneğin, Beck'in (1979) bilişsel modeline göre bilişin duyguları etkilediği ve duyguların oluşmasında aktif rol oynadığı düşünülürken; Greenberg (2015), Matsumoto ve Ekman (2008) gibi araştırmacılar duygunun bilişi etkilediğini düşünmektedirler. Öte yandan Ledoux (1994) duygu ve bilişin beyinde spesifik bir yerinin olmadığını ancak birbirleriyle olan etkileşimlerinin nöronal düzeyde olduğunu belirtmektedir. MacLean'ın (1990) üçlü beyin modeline tekrar dönüldügünde bilişin daha çok neo kortekse denk gelen neo memeli bölümünde, duygunun ise daha çok limbik sisteme denk gelen paleo memeli bölümünde yer aldığı söylenebilir. Bu çerçevede ise duygu ve bilişin kaynaklarının birbirlerinden oldukça farklı olduğu görülmektedir. Bu iki yapının birbirlerini etkileme düzeyine bir örnek verilmesi gerekirse, psikolojik danışma oturumlarında bazen danışanlar herhangi bir duygu hissetmezken süreç içerisinde olumsuz anılarını hatırlayabilmektedir. Bilişin devreye girmesiyle bu anılar konuşulmakta ve olumsuz düşünceler olumsuz duyguları hissettirebilmektedir. Örnekte de görüldüğü üzere her ne kadar duygu beyin yapısında daha temel düzeyde konumlansa da üst katmanda yer alan bilişin duygunun oluşmasına sebebiyet verdiği görülmektedir. 


\section{Yüz İfadeleri ve Duygular}

Yüz ifadeleri kavramı ile "yüzdeki mimetik kasların hareketleri" anlatılmak istenmektedir (Ekman ve Friesen, 2008). Dolayısıla yüz ifadeleri veya yüzdeki kas hareketleri; duyguları, bilişi, fizyolojiyi kapsayan geniş bir kavramdır. Yüz ifadelerine yönelik ilk çalışmanın 1824 yılında Charles Bell tarafindan kaleme alınan Anatomy and Physiology of Expression eser olduğu görülmektedir (Desmond ve Moore, 2017). Bazı kaynaklarda Essays on the Anatomy and Physiology of Expression olarak geçen bu eserde, yüzdeki kasların insanın özgün ahlaki doğasını betimleyen duyguları yansıttığı ve bu duyguların oluşmasını sağlayan kaslarla donatıldığı ileri sürülmektedir (Desmond ve Moore, 2017). 1872 yılında ise alanyazında yüz ifadelerindeki duygular konusuna ilişkin temel kaynak olarak nitelendirilen The Expression of the Emotions in Man and Animals adlı eser yayınlanmıştır (Darwin, 1872/1998). Bu çalışmanın Bell'in çalışmasından farkı ise yazarların yüz ifadelerindeki kasların temsil ettiği şeyin ne olduğuydu. Darwin, yüz ifadelerinin duyguları yansıttığını ileri sürmekte ve bu ifadelerin insanları eşsiz kılan bir özellik olmadığına inanmaktadır. Gözlemlerine dayanarak hayvan ve insanlarda bazı duyguların benzer ifadelerle oluştuğunu ileri sürmektedir. Bir başka deyişle insanlarda oluşan yüz ifadeleri hayvanlarınkinden farklı değildir. Darwin'in bu görüşüyle yüz ifadelerinde beliren duyguların evrensel olduğu düşüncesinin tohumları atılmıştır denilebilir. 1900'lü yılların başlarında yüz ifadelerindeki duyguların kültüre özgü olduğu düşüncesi gündeme gelmesine ek olarak yüz ifadelerinin duyguları yansıttığ 1 fikri de kabul edilmekte olduğu görülmektedir. Ayrıca duyguların tanınmasıyla ilgili çalışmaların kontrollü ve doğal ortamlarda yapılmıştır (Russell ve Fernandez - Dols, 1997). Yüz ifadelerindeki duygulara yönelik modern çalışmanın ise Tomkins (1962) ile başladığını söylenebilir. Darwin'in gözlemlerinden etkilenen Tomkins, yüz ifadelerindeki duyguların tüm insanlarda benzer şekilde oluştuğunu düşünmektedir (Tomkins, 1962). Bu çalışmayla, yüz ifadelerindeki duyguların evrensel olduğu görüşünün filizlendiği benzetmesinde bulunulabilir. Daha sonra ise Ekman, Sorenson ve Friesen (1969) tarafından yapılan araştırma ile yüz ifadelerindeki duyguların evrensel olduğu görüşüne ilk kanit elde edilmiştir. 
Her ne kadar yüz ifadelerine ilişkin çalışmaların duygularla ilişkisine odaklanılsa da yüz ifadelerinin sadece duyguları ilettiği söylenemez. Dolayısıyla yüz ifadeleri birtakım işlevleri de kapsamaktadır. Örneğin, kişi meraklı veya bir konuya ilgisi olduğunda kaşlarını kaldırabilmektedir. Kurulan bir diyalogda yüz ifadeleri aracılığıyla konuşmanın bittiğine veya konunun değiştirilmesi gerektiği aktarılabilmektedir. Odaklanma durumunu kapsayan bilişsel süreçlerde kaşların çatılması gibi yüz ifadesinde birtakım değişiklikler oluşabilmektedir. Bunun yanı sıra yaşamımızın ayrılmaz parçalarından olan konuşma, yemek yeme ve telaffuzda yüz ifadelerinde kullanılması söz konusudur (Matsumoto ve Ekman, 2008).

Genel olarak bakıldığında yüz ifadeleriyle ilgili çalışmaların duygularla ilişkili olduğu görülmektedir. Nitekim Ekman ve Friesen (2003) yüz ifadelerinin duyguların görülmesine aracılık ettiği ve duyguların ortaya çıktığ 1 ilk yerin yüz bölgesi olduğunu belirtmektedirler. Fizyolojik ve bilişsel boyutların yüz ifadelerini etkilemesine yönelik araştırmaların geri planda kaldığı söylenebilir. Camras, Fatani, Fraumeni ve Shuster (2016) tarafından aktarılan bilgiye göre, yüz ifadeleriyle duygu ilişkisinin kabul edilmesindeki iki sebepten birincisi bebeklerin duygudurumlarına ilişkin sözel ifadeleri olmamasından ötürü sözsüz belirtilerine güvenilmesi, ikincisi ise duygu kavramını ele alan önemli (örneğin, Ekman, 1971; Izard, 1991; Tomkins, 1962) kuramcıların çalışmalarında yüz ifadeleri ve duygu arasındaki bağı kanıtlamalarıdır.

\section{Temel Duygular}

Alanyazın incelendiğinde temel duyguların içerisinde hangi duygular olacağına yönelik çeşitli tartışmalar bulunmaktadır. Bu tartışmaya geçilmeden önce temel duyguların karakteristik özelliklerinin sıralanması yerinde olacaktır. Bir başka deyişle bir duyguya temel duygu denilebilmesi için gerekli ölçütler aşağıda belirtilmektedir.

Ekman ve Cordaro'ya (2011) göre temel duyguların ayırt edici evrensel ve fizyolojik belirtilerinin olması, otomatik uyarılma sonucu oluşması, duyguları ortaya çıaran tetikleyicilerinin benzer olmasının yanı sıra diğer primatlarda da benzer belirtilerinin olması gerekmektedir. Bu konuya açıklık getirilmesi gerekirse, şempanzeler üzerinde yapılan araştırmalar 
örnek verilebilir. Bu araştırmalarda şempanzelerin temel duygu ifadelerini insanlara oldukça benzer yüz hareketleriyle yansıttıkları sonucuna ulaşılmıştır (Bard, 2003; Burrows, Waller, Parr ve Bonar, 2006). Temel duyguların bir diğer özelliği hızlı ve kısa sürede oluşabilmesidir. Ayrıca kendiliğinden oluşabilmesi, ayırt edici düşünceler, anılar ve öznel yaşantıların olması, gelişimsel olarak kendine özgü olması, sınırlandırılmış bir hedefinin olmaması ve her türlü olayda ortaya çıkabilmesini içermektedir.

Ekman'a (2007) göre bu ölçütlere uyan yedi duygu bulunmaktadır: öfke, mutluluk, üzüntü, şaşkınlık, tiksinme, korku ve aşağılama. Bazı araştırmacılar utanç, merak ve suçluluk duygularının da temel duygular olabileceğini ileri sürmektedirler (Izard, 1977). Yakın tarihte yapılan bir araştırmada duygularla çalışan bilim insanlarının temel duygulara ilişkin görüşleri alınmıştır. Bu araştırma sonuçlarına göre katılımcıların geneli öfke (\%91), korku (\%90), tiksinme (\%86), üzüntü (\%80) ve mutluluk (\%76) duygularını temel duygular kategorisinde incelemekte olduğu bulgusuna ulaşılmıştır (Ekman, 2016). Her ne kadar bilim insanları çoğunluk olarak beş duyguda birleşse de Ekman (2016) temel duygu sayılarının artabileceğini düşünmektedir.

\section{Yüz İfadelerindeki Duygular Evrenseldir}

Yüz ifadelerindeki duyguların evrensel olduğu fikri Darwin (1872/1998) ile ortaya çıkmış Tomkins (1962) ile bu görüş devam etmiştir. Ekman (1971) tarafından yapılan araştırmalarla bu görüşün kanıtları sağlanmıştır. Daha öncede belirtildiği üzere yüz ifadelerindeki duyguların evrensel olduğu görüşünün ilk kanıtı olarak Ekman, Sorenson ve Friesen (1969) tarafından yapılan çalışma olduğu görülmektedir. Araştırmacılar tarafından farklı kültürlerden gelen katılımclara duygu ifadelerinin (yüz ifadelerindeki duygular) olduğu resimler gösterilmiştir. Katılımclardan ise gördükleri resimlerdeki duygu ifadelerinin ne olduğunu belirtmeleri istenmiştir. Farklı kültürden gelen katılımcıların "mutluluk, öfke, tiksinme, korku, şaşkınlık ve üzüntü" duygularını yüksek düzeyde doğrulukla tanımışlardır. Bu bulgu, yüz ifadelerindeki duyguların evrensel olduğu görüşünü desteklemekte ancak birtakım belirsizlikleri de beraberinde getirmektedir. Örneğin, araştırmanın katılımcıları görsel iletişim araçlarından 
etkilenmiş olup yüz ifadelerindeki duyguları tanımış veya kendi kültürlerinden bu ifadeleri tanımayı öğrenmiş olabilirler. Bunun üzerine Ekman ve Friesen (1971) tarafından başka bir çalışma daha yapılmıştır. Bu çalışmada araştırmacılar tarafından Afrika kıtasında bulunan Papua Yeni Gine' deki insanların yüz ifadeleri incelenmişlerdir. Araştırmacıların böyle bir ülkeye gitmelerinin sebebi olarak ülkenin insanlarının görsel iletişim araçlarından çok daha az etkilenmiş olmalarından kaynaklanmaktadır. Araştırmanın katılımcıları olan kabile üyeleriyle tanışılmasını takiben kabile üyelerine altı temel duyguyu (mutluluk, öfke, tiksinme, korku, şaşkınlık ve üzüntü) betimleyen öykülerden bahsedilmiştir. Daha sonra kabile üyelerinden bahsedilen öykülerdeki duygu ifadelerinin araştırmac1lar tarafından hazırlanmış olan yüz ifadeleri fotoğrafıyla eşleştirmeleri istenmiştir. Devamında ise katılımclardan betimlenen duygu ifadelerindeki kişi olsaydılar yüz ifadelerinde nasıl bir değişiklik olacağını ifade etmeleri istenmiştir. Bu yönerge verildikten sonra araştırmacılar tarafından katılımcların yüz ifadeleri kamera kaydına alınmıştır. Toplanan bu verilerle birlikte Amerika'ya dönüldükten sonra Amerikalı katılımcılara bu filmler izlettirilmiş ve katılımclardan kamera kaydında gördükleri duygu ifadelerinin yani Papua Yeni Gineli katılımcıların yüz ifadelerindeki duyguların ne olduğu sorulmuştur. Amerikalı katılımcılar bu ifadeleri yüksek bir düzeyde doğru tanımışlardır.

Evrenselliğe ilişkin üçüncü bir araştırma yine Ekman (1971) tarafından yapılmıştır. Bu araştırmaya katılan kişiler farklı kültürlerden gelmektedir: Amerika ve Japon toplumundan gelen katılımcılar. Araştırmacı tarafından duygu içerikli çeşitli video klipler hazırlanmıştır. Daha sonra ise bu video klipler her iki kültürdeki katılımcılara da izletilmiştir. Buradaki amaç video kliplerin katılımcıların yüz ifadelerinde duygu oluşmasını sağlamasıdır. Dolayısıyla da katılımcıların yüz ifadeleri kamera kaydına alınmıştır. Nitekim yüz ifadelerindeki belli başlı duygular evrensel ise farklı kültürlerden gelen katılımcıların yüzlerinde benzer şekilde oluşması gerekmektedir. Araştırmanın sonucuna göre hem Amerikalı hem de Japon katılımcıların yüz ifadelerinde benzer kas hareketleri gözlenmiştir. $\mathrm{Bu}$ araştırmanın bir başka bulgusu daha bulunmaktadır. Katılımcılar tarafından video klip izlendikten sonra katılımcılarda oluşan duygunun yüzde kaldığı süre değişiklik göstermektedir. Olumsuz duygu içerikli video klip izletildiğinde Japon katılımcılar Amerikalı katılımcılara kıyasla 
deneyimledikleri duyguyu yüz ifadelerinde daha kısa sürede göstermişlerdir. Bir başka deyişle, olumsuz duygu oluştuğunda Amerikalı katılımclların yüz ifadelerinde duygu daha uzun süre kalmaktadır. Bu durum Ekman (1971) tarafından yüz ifadelerinde görülen belli başlı duyguların bütün insanlarda görüldüğü ancak duygunun yüz ifadelerinde görülme süresinin kültürel faktörlerden etkilendiği şeklinde yorumlanmıştır.

Yüz ifadelerinde görülen duyguların evrensel olduğu bu araştırmalarla sağlam temellere dayandırılmıştır. Ayrıca yüz ifadelerinin tanınmasına ilişkin otuzdan fazla ifadenin evrensel olduğunu destekleyen çalışmaların olduğu belirtilmektedir (Matsumoto, 2001). Bir başka deyişle yüz ifadelerindeki duyguların evrensel olmasına yönelik yapılan ilk araştırmalar daha sonra yapılan birçok araştırmayla desteklenmiştir.

\section{Yüz İfadelerindeki Duygular Doğuştandır}

Yüz ifadelerindeki duyguların evrensel olduğu birçok araştırmalarla desteklenmesine ek olarak araştırmacıların merak ettikleri bir diğer konu, yüz ifadelerindeki duyguların doğuştan mı yoksa öğrenilmiş olduğuydu. Bu konuya açıklık getirmek için Izard (1994) yapılacak olan araştırmaların dil ve anlamsal ifadelere bağlı kalınmaması gerektiğini vurgulamaktadır. Bu çerçevede dört ve altı aylık bebekler üzerinde yapılan bir araştırmada bebeklerin yüz ifadelerindeki duyguları ayırt edebilme becerileri incelenmiştir. Bebeklere yüz ifadelerindeki duyguları (mutluluk ve öfke) ve nötr ifadeyi yansıtan resimler gösterilmiştir. Araştırmanın sonuçlarına göre henüz bir yaşında olmayan bebekler kendilerine gösterilen resimlere farklı tepkiler vermişlerdir. Bir başka ifadeyle bebekler, mutluluk ve öfke duygularını ayırt edebilmektedirler. Bebekler üzerinde yapılan başka çalışmalarda da bebeklerin yüz ifadelerini ayırt edebildikleri gözlenmiştir (örneğin, Field et al., 1983; Kagan ve Lewis, 1965). Bunlar, yüz ifadesindeki duygunun tanınmasına ilişkin olan kanıtlardır. Ayrıca katılımcıların yüz ifadelerinde oluşan duyguların tespitine yönelik çalışmalar da bulunmaktadır. Bu bağlamda doğuştan gözleri görmeyen ve görme duyusunda sorun olmayan katılımcılar üzerinde yapılan araştırmalar bulunmaktadır (Galati, Miceli ve Sini, 2001; Galati, Sini, Schmidt ve Tinti, 2003). Bir başka gözleri görmeyen bireyler üzerinde yapılan araştırmada katılımcların yüz ifadelerinde oluşan spontan duygular incelenmiştir. 2004 y1lında 
Atina Paralimpik Oyunlarına katılan 84 judo atletin spontan oluşan ifadeleri kamera kaydına alınmıştır. Katılımcıların yüz ifadeleri FACS ile analiz edilmiştir. Bu çerçevede madalya alan ve beşinci olan 39 atlet değerlendirmeye alınmıştır. Katılımcılar; doğuştan gözleri görmeyenler, sonradan görme duyusunu yitirenler ve görenler (kontrol grubu) olmak üzere üç grupta incelenmiştir. Katılımcıların yüz ifadeleri fotoğrafları analiz edildiğinde, görmeyen atletlerin spontane oluşan duygu ifadeleriyle benzer duygu ifadesinin oluştuğu gören atletler (kontrol grubu) arasında benzer AU hareketleri görülmüştür. Bir başka deyişle, gözleri gören ve görmeyen katılımclar benzer duyguları yaşadığında benzer yüz hareketleri göstermektedir. Bu sonuç ise duyguların yüz ifadesinde spontan oluşmasının sonradan öğrenilmediği ancak sosyal hayatta yüz ifadelerinin şekillenmesinin öğrenmeyle ilişkili olduğunu göstermektedir (Matsumoto ve Willingham, 2009).

\section{Kültür ve Yüz İfadelerindeki Duygular}

Yüz ifadelerindeki duyguların evrensel olduğu (Ekman, 1971) daha önce de belirtilmesinin yanı sıra bu ifadelerin kültürel birtakım faktörler tarafından da etkilendiği söylenebilir. Bu faktörlerden birisi cinsiyettir. Nitekim yapılan bir araştırmada Japon katılımclara duygu ifadeleri resimleri gösterilmiştir. Resimdeki yani fotoğraftaki kişinin cinsiyeti kadın olduğunda Japon katılımcılar duygu ifadelerini daha kolay tanımışlardır (Matsumoto, 1992). Yine benzer bir başka araştırmada fotoğraftaki kişinin kadın olması durumunda duygu ifadelerinin tanınma oranı daha yüksektir (Hampson, van Anders ve Mullin, 2006).

Cinsiyete göre yüz ifadelerindeki duyguları tanıma becerilerine ilişkin yapılan kapsamlı bir araştırmada katılımcılar Amerika ve Avrupa kıtalarından seçilmiştir. Toplamda 42.638 kişiye ulaşıldıktan sonra katılımcılara temel yüz ifadelerinin olduğu resimler (mutluluk, öfke, şaşkınlık, üzüntü, korku, tiksinme ve aşağılama) gösterilmiştir. Uyrukları dikkate alınmaksızın kadın katılımcılar yedi temel duyguyu erkeklere kıyasla daha doğru tanımışlardır (Merten, 2005).

Kadın katılımcıların erkek katılımcılara kıyasla yüz ifadelerini daha tanıdıkları bulgusuna ulaşılan araştırmalara (Boyatzis, Chazan ve Ting, 1993; Hall ve Matsumoto, 2004) ek olarak yüz ifadelerini tanımada her iki 
cinsiyet arasında manidar düzeyde bir fark olmadığına dair araştırmalar da bulunmaktadır (Domico, 2011; Mitchell, 2006). Tartışmalı bir konu olan cinsiyet faktörüne açıklık getirmek amacıyla yapılan bir meta-analiz çalışmasına göre kadın katılımcılar erkek katılımcılara kıyasla düşük düzeyde de olsa yüz ifadelerindeki duyguları daha doğru tanımaktadırlar (Thompson ve Voyer, 2014).

Kadınların yüz ifadelerini tanımada erkeklerden daha iyi olmasının sebeplerinden birinin kadınların itaatkâr olmalarından kaynaklanabileceği düşünülmektedir. Kadınların geleneksel toplumsal itaatkarlığı yüz ifadelerindeki duyguları daha iyi tanıyabilmelerinin sebebi olarak gösterilmektedir (Snodgrass, 1992).

Yüz ifadelerindeki duyguların tanınmasını etkileyen faktörlerden bir diğeri de yüz ifadeleri fotoğraflarında gösterilen kişinin katılımcıyla aynı kültürden olması durumunda ifadelerin daha doğru tanınmasıdır. Bu durum "grup avantajı" olarak ifade edilmektedir (Elfenbein ve Ambady, 2002). Bir başka ifadeyle katılımcı ile fotoğraftaki/görseldeki kişi aynı topluma ait olduklarında katılımcılar bu ifadeleri daha iyi tanıyabilmektedirler.

Bireyin fizyolojik durumu da yüz ifadelerindeki duyguları tanınmasını etkileyebilmektedir. Örneğin, yapılan bir araştırmada kadın katılımcılar folliküler dönemde olduklarında yüz ifadelerindeki duyguları daha iyi tanıyabilmekteyken progesteron yani döngünün 14. gününden sonra salg1lanan ve şişkinlik şikayetine sebep olan dönemde yüz ifadelerindeki duyguları tanımada daha düşük performans göstermektedirler (Derntl ve dig.., 2008). Bir başka fizyolojik durum olan uykusuzluk hali, yüz ifadelerinin tanınmasını olumsuz yönde etkilemektedir (Killgore, Balkin, Yarnell ve Capaldi II, 2017). Yapılan araştırmalar göz önünde bulundurulduğunda fizyolojik durum, yüz ifadelerindeki duyguların tanınması etkilemektedir.

Kişiliğin ifadeleri tanınmasındaki etkisi ise tartışmalıdır. Matsumoto ve diğerleri (2000) tarafından yapılan araştırmada beş faktör kişilik boyutlarından açıklık ve özdenetim puanları yüksek kişiler duygu ifadelerini daha doğru tanıyabildikleri bulgusuna ulaşılmıştır. Ancak Zhang ve Parmley (2011) bireyin kişilik özelliklerinin duygu ifadelerini tanımadaki etkilerinin tartışılabilmesi için bu konuda güçlü kanıtlara ihtiyaç duyulduğunu ileri sürmektedirler. 
Genel olarak bakıldığında, yüz ifadelerindeki duyguların tanınmasını etkileyen birçok faktör bulunmaktadır. Gündelik ilişkilerimizde bazen karşımızdaki kişinin ne hissettiğini kaçırdığımız anlar olmaktadır. O anki yoğunluğumuz, zihinsel meşguliyetimizin yanı sıra yukarıda sıralanan faktörler karşımızdaki kişinin duygularını tanıyamamamıza veya onun hissettiği duyguya kaçırmamıza sebep olabilmektedir. Ayrıca duygu ifadeleri bazen saliseler içerisinde başlayıp sona erebilmektedir. Bu durumda duygu ifadelerinin tanınmasını etkileyebilmektedir. Bir sonraki başlıkta yüz ifadelerinin türleri açıklanacaktır.

\section{Yüz İfadelerinin Türleri}

Yüz ifadelerindeki duyguların oluşması bazı yönler açısından birbirlerinden ayrılmaktadır. Duygu ifadesinin oluşma süresi, yüzdeki kasların gerilme düzeyi gibi farklar bulunmaktadır. Bu ifadeler dört başlık altında toplanmaktadır: makro ifadeler, mikro ifadeler, gizli ifadeler ve kısmi ifadeler (Matsumoto, Frank ve Hwang, 2013, s.37).

Makro İfadeler: Bu ifadeler yüz bölgesinde genelde 0.5 ile 4 saniye kadar sürmekte ve yüzün tüm bölgesindeki ilgili kasların hareket etmesi sonucu oluşmaktadır (Ekman, 2007). Gündelik ilişkilerde sıklıkla karşılaşılan duygu ifadesidir. Bu tür ifadelerin tanınması kolaydır.

Mikro Iffadeler: Mikro ifadeler “bir saniyeden daha kısa sürede beliren (saniyenin $1 / 5^{\prime}$ i ile saniyenin $1 / 25$ kadar sürede), bilinçli olarak ortaya çıkmayan ve evrensel olan anlık yüz hareketleri" olarak tanımlanmaktadır (Ekman ve Friesen, 1969, s.94). Mikro ifadeler ilk olarak Haggard ve Isaacs (1966) tarafından keşfedilmiştir. Keşfedilmesini takiben üç yıl sonra Ekman ve Friesen (1969) tarafından da fark edilmesiyle mikro ifadeler üzerine yapılan çalışmaların arttığı görülmektedir. Mikro ifadelerinin kökeni Darwin'in çalışmalarına uzandığı söylenebilir (Ekman, 2003). Darwin'e göre kişi bir duygusunu bastırmak istediğinde bu duygusunun ortaya çkmasını engelleyemez ve oluşan duygu anlık da olsa oluşur. Dolayısıyla bu açıklama mikro ifadelerle ilgili benzerlik göstermektedir. Gündelik ilişki- 
lerde mikro ifadelerin tanınması zor olabilmektedir. Nitekim oluşma süresinin bir saniyeden daha kısa sürmesi bu ifadelerin görülmesini engelleyebilmektedir.

Gizli Ífadeler: Bu ifadeler ise yüzdeki ilgili kasların tamamının yüksek yoğunlukla hareket etmesiyle oluşan makro ifadelerin aksine, kişi duygu hissetmeye başladığında veya duygusunu baskılamaya çalışırken oluşan düşük yoğunluktaki duygu ifadeleridir (Matsumoto, Frank ve Hwang, 2013, s.38). Bu ifadeler oluştuğunda yüzdeki ilgili tüm kasların hareketi oluşabilir ancak buradaki kas gerilmeleri düşük düzeydedir. Yüzdeki ilgili tüm kasların hareket etmemesi veya duyguya ilişkin belirli kasların hareketi halinde oluşan ifadeye de kısmi ifadeler denmektedir. Örneğin, üzüntü duygusu oluştuğunda kaş ve dudak bölgesindeki kaslarda değişimler meydana gelmektedir. Buradaki üzüntünün yoğunluğu düşük olduğunda gizli ifade olabilir. Ancak üzüntü duygusu sadece kaşların olduğu bölgede bir değişikliğe yol açıor ve dudak bölgesinde herhangi bir değişime yol açmıyorsa veya tam tersi bir durum söz konusu olduğunda ve bu durum düşük yoğunlukta gerçekleştiğinde oluşan ifadeye de kısmi ifade denmektedir.

\section{Yüz İfadelerindeki Duyguların Ölçülmesi ve Değerlendirilmesi}

Yüz ifadelerindeki duygularla ilgili araştırmaların yöntemsel açıdan bazı farklılıkları bulunmaktadır. Alanyazın incelendiğinde yüzdeki kas hareketlerine ilişkin iki yöntemin kullanıldığı görülmektedir. Bunlardan ilki katılımcıların kendi yüz ifadelerine yönelik araştırmalar iken; ikincisi katılımcılara gösterilen yüz ifadeleri fotoğraflarının onlardan tespit edilmesi istenen araştırmalarıdır. Bir başka ifadeyle ilki katılımcının yüz ifadesindeki kasların araştırmacı tarafından incelenmesiyken (encoding); ikincisi, katılımclara gösterilen yüz ifadeleri fotoğraflarının katılımcı tarafından değerlendirilmesidir (decoding). Bu iki yöntemsel farklılığı kendi içlerinde gruplara ayırmak mümkündür. Şekil 1.'de görüldügü üzere ifadenin oluşmasında elektromiyografi ve kod sistemleri bulunmaktayken; ifadenin tanınmasında serbest seçim ve zorunlu seçim bulunmaktadır. 


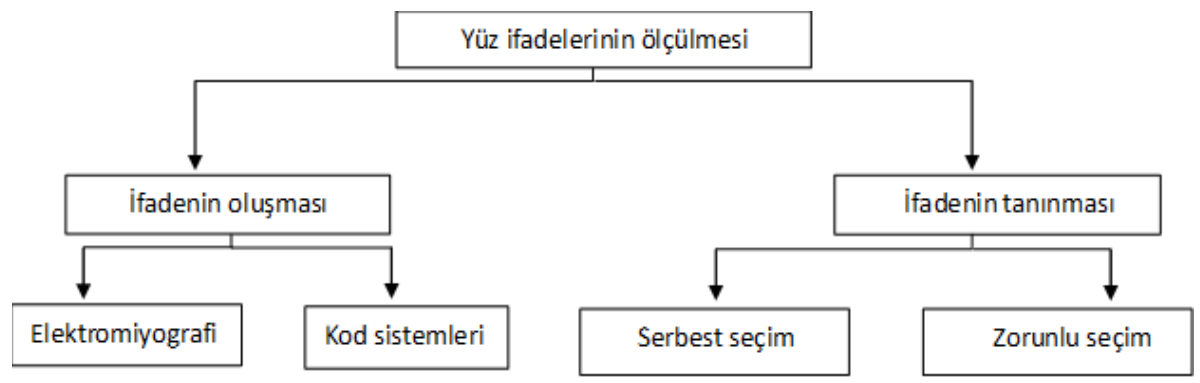

Şekil 1. Yüz İfadelerinin Ölçülmesi.

Alanyazında yüz ifadelerindeki duyguların ölçülmesinde ifadenin oluştuğu andaki kas hareketlerinin tespitine ilişkin araştırmaların bazılarında elektromiyografi yöntemi kullanılmaktadır. Bu ölçme aracıyla yüzdeki kas yüzeylerine küçük elektrotlar yerleştirilmekte ve hangi kasın ve/veya kasların hareket ettiğine ilişkin bilgi sağlamaktadır. Bu yöntemin yüz hareketlerinin ölçülmesinde en objektif yol olmasına karşın pek tercih edilen yöntem olmadığı belirtilmektedir. Bunun sebebinin ise katılımcıların yüzüne yerleştirilen elektrotlardan ötürü yüz hareketlerinde güvenilir olmayan sonuçlar ortaya çıabilmesi ve ekonomik bir yöntem olmamasından kaynaklanmaktadır (Russell ve Fernandez - Dols, 1997). İkincisi kat1lımcının yüz ifadelerinde oluşan duyguların analiz edilmesini sağlayan kodlama sistemleridir. Yaygin kullanılan kodlama sistemleri arasında Yüz Hareketleri Kodlama Sistemi (Facial Action Coding System - FACS) bulunmaktadır. Ekman ve Friesen (1978) tarafından geliştirilen bu kodlama sisteminde katılımcının yüz ifadesindeki kas hareketlerinin kodlaması yapılmaktadır. Örneğin, FACS'teki kodlamalardan biri olan AU 1 (Action Unit 1), "kaşların iç kısımlarının yükselmesi" hareketini temsil eder (Ekman ve Rosenberg, 2005). Bir başka ifadeyle AU 1 hareketi, üzüntü duygusu yaşandığında görülen kaş hareketidir. Bu kodlama sisteminin bir başka versiyonu Duygusal Yüz Hareketleri Kodlama Sistemidir (Emotion Facial Action Coding System-EMFACS). EMFACS ile duyguların yüzdeki hareketleri gruplandırılmaktadır (Ekman ve Friesen, 1983). Alanyazında rastlanan farklı kodlama sistemleri de bulunmaktadır. Örneğin; Izard, Dougherty ve Hembree (1983) tarafından geliştirilen Bütüncül Değerlendirmeyle Duygulanım İfadelerini Tanıma Sistemi (System for 
Identification Affect Expression by Holistic Judgment - AFFEX), bir diğeri Izard (1979) tarafından geliştirilen Azami Ölçüde Tanımlayıcı Yüz Hareketleri Kodlama Sistemi'dir (Maximally Descriptive Facial Movement Coding System - MAX). Şekil 1.'de belirtilen yöntemlerin ifadenin oluşmasında ve ifadenin tanınmasında keskin bir ayrım yapılmamasına karşın, yüz ifadelerindeki duygularla ilgili araştırma yöntemlerinin genel hatlarıyla ele alınması sağlanmaktadır. Örneğin bir derleme çalışmasında elektroensefalografi (EEG) yönteminin yüz ifadelerinin tanınmasında kullanılabileceği ve yüz ifadelerinin nörobiyolojisine ilişkin bilgi verebileceği belirtilmektedir (Paiva - Silva, Pontes, Aguiar ve de Souza, 2016). Bu yöntem her ne kadar elektromiyografi yöntemiyle benzerlik gösterse de bazı farklılıkları da bulunmaktadır. Bir başka ifadeyle EEG, elektromiyografi yöntemine benzer bir yöntemdir.

Yüz ifadelerindeki duyguların değerlendirilmesinde kullanılan bir başka yöntem ise ifadenin tanınmasıdır. Araştırmacı tarafından gösterilen fotoğrafların katılımcılar tarafından tanınması istenmektedir. Burada iki seçenek bulunmaktadır. Katılımclara verilen yönerge "fotoğrafta gördüğünüz duyguyu yazınız" şeklinde olduğunda katılımcılardan serbest seçim yapmaları istenmekteyken; katılımcılara "fotoğrafta gördüğünüz duygulara en yakın seçeneği işaretleyiniz" yönergesiyle de katılımcılara zorunlu bir seçim yaptırılmaktadır. Her iki yöntem de araştırmanın niceliğini belirleyen hususlardır. Özellikle kültürler arası çalışmalarda duygu ifadesini kelimeye dökmek, çalışmanın yapıldığı toplumun dilinden ötürü farklılık gösterebilmektedir. Bu bağlamda araştırmacının serbest seçim yöntemini kullanması doğru olabilir. Yüz ifadelerindeki duyguların evrensel olmasına ilişkin çalışmalarda dil, dikkat konusu olmuştur. Bu konuda Izard (1994) doğuştanlık ve evrensellik konularında dilden bağımsız araştırmalar yürütmek için dilin kontrol altında olması gerektiğini vurgulamaktadır.

İfadenin tanınmasında araştırmacı katılımcılara yüz ifadelerindeki duyguları yansıtan fotoğraflar göstermektedir. Alanyazında sıklıkla kullanılan fotoğraf seti Ekman ve Friesen (1976) tarafından geliştirilen duygusal yüz fotoğrafları setidir. Orijinal adı Pictures of Facial Affect (POFA) olan fotoğraf setinde altı temel duygu (mutluluk, şaşkınlık, tiksinme, üzüntü, korku ve öfke) siyah-beyaz fotoğraflarda gösterilmektedir. Bu fo- 
toğraf seti FACS ile güvenilir bir şekilde ( $r=.91)$ kodlanmıştır. Yüz ifadelerindeki duyguların tanınmasında sıklıkla kullanılan bir başka fotoğraf seti ise Duyguların Japon ve Amerikalı Yüz İfadesidir (Japanese and Caucasian Facial Expression of Emotion-JACFEE). Matsumoto ve Ekman (1988) tarafından geliştirilen bu fotoğraf setinin çeşitli versiyonları bulunmaktadır (Humintell, 2018). JACFEE'de yedi duygu (mutluluk, öfke, tiksinme, korku, şaşkınlık, üzüntü ve aşağılama) ve nötr ifade, renkli fotoğraflarda gösterilmektedir. POFA'da olduğu gibi bu ölçme aracı da FACS ile ( $\mathrm{r}=.91)$ kodlanmıştır (Ekman ve Rosenberg, 2005). Bu kodlamalara bir örnek verilmesi gerekirse AG-1C09 olarak isimlendirilen fotoğraf aşağılama ifadesini göstermektedir. Bu fotoğrafın kodlama sistemindeki karşılığı AU (12B+14C)'dir. AU kodlarından "12" ve "14" sayıları yüzdeki farklı kas hareketlerini; " $B$ " ve " $C$ " harfleri ise kasın gerilme düzeyini yani duygu yoğunluğunu ifade etmektedir.

Son olarak yüz ifadelerindeki duyguların ölçülmesi ve değerlendirilmesinde dikkat edilmesi gereken önemli bir konunun ekolojik geçerlik olduğu belirtilmektedir. Yüz ifadelerinin oluşmasında veya tanınmasında katılımcıyı etkileyen hususların doğal koşullar mı yoksa kontrol altındaki koşullar mı olduğu bilinmelidir. Ortamdan veya çevreden kaynaklanan farklılıklar duyguların oluşmasını etkilemektedir (Russell ve Fernandez Dols, 1997).

\section{Sonuç}

Duyguları belirleyebilme, insanın yaşamında oldukça önemlidir. Duyguları belirleme; öfke, üzüntü gibi bir duygunun sözel olarak isimlendirme anlamına gelmektedir. İnsan yaşamında önemli bir yeri olan duygular ve yüz ifadeleri 1824 yılından beri alanyazında yer edinmektedir. Bu çerçevede yapılan araştırmalar sonucunda yüz ifadelerindeki duyguların tüm insanlar tarafından benzer şekilde görüldüğü anlaşılmıştır. Bunun yanı sıra araştırma bulguları, duygu ifadelerinin oluşmasının birtakım kültürel ve çevresel faktörlerden etkilendiğini göstermektedir. Yüz ifadelerine ilişkin yapılan araştırmaların ise yöntemsel farklılıkları bulunmaktadır. Katılımcının yüz ifadesini inceleyen araştırmaların genellikle kod sistemle- 
riyle tespit edildiği; katılımcılara gösterilen fotoğrafların ise kodlama sistemine göre oluşturulmuş yüz ifadeleri görsellerinden oluştuğu belirtilmektedir.

Bütün bunlardan hareketle uluslararası alanyazın incelendiğinde yüz ifadelerindeki duygulara ilişkin birçok çalışma bulunmasına rağmen ulusal alanyazında bu konuyla ilgili çalışmaların sınırlı olduğu görülmektedir. Bu derleme çalışmasıyla ülkemizdeki bu boşluğun doldurulması hedeflenmiştir. Ayrıca yüz ifadelerine ilişkin çalışma yapacak araştırmacılara da ışık tutacağı düşünülmektedir. Bu bağlamda araştırmacıların toplumsal çevrede yüz ifadelerinin rolü, yüz ifadelerinin türlerine göre (makro, mikro, gizli ve kısmi ifadeler) tanınma farklılıkları gibi çalışmalar yapacak olmasıyla duygu ifadelerinin daha kapsamlı ele alınmasını sağlayacağ1 düşünülmektedir. Ulusal alanyazında psikiyatri (örneğin, Kadak, Demir ve Doğangün, 2013; Tatar, Yargıç, Oflaz ve Büyükgök, 2015) ve psikoloji (örneğin, Gülbetekin, Bayraktar, Özkan, ve Özkan, 2017) alanlarında yüz ifadelerindeki duygulara yönelik çalışmalar bulunmasına rağmen mikro ifadelere ilişkin bir araştırmaya rastlanmamıştır. Yüz ifadelerindeki duyguların iletişimdeki önemi göz önünde bulundurulduğunda önerilen çalışmaların yapılması bu konuda ışık tutacaktır. 
EXTENDED ABSTRACT

\title{
Emotions in Facial Expression: Review
}

$*$

\author{
Ahmet Metin \\ Erciyes University
}

Human nature has been tried to be understood for centuries. Recent research emphasizes the importance of emotion in human life (Ekman \& Friesen, 1971; Ekman \& Friesen, 1986; Ekman \& Friesen, 2003; Izard, 1977; Izard, 1991; Greenberg, 2006; Greenberg \& Safran, 1989; Gülbetekin, Bayraktar, Özkan, \& Özkan, 2017; Panksepp, 2004; Sloan, 2004; Tatar, Yargıç, Oflaz \& Büyükgök, 2015).

Emotion has important functions in human life and motivation (Matsumoto, Frank \& Hwang, 2013). For example, fear can provide the survival of one's life; anger provides protection of the self (Greenberg, 2011). Emotion first appears in the facial region, therefore facial expressions mediate the recognition of emotions (Ekman \& Friesen, 2003).

The first study of facial expressions in 1824 by Charles Bell "Anatomy and Physiology of Expression" (Desmond \& Moore, 2017). However, in 1872, his work Darwin "The Expression of the Emotions in Man and Animals" (Darwin, 1872/1998) was described as the main source of emotions in facial expressions. Darwin argues that facial expressions reflect emotions and that these expressions are universal.

It can be said that the modern study of emotions in facial expressions started with Tomkins (1962). Impressed by Darwin's observations, Tomkins thinks that the emotions in facial expressions are similar to all humans (Tomkins, 1962). Afterwards, the research by Ekman, Sorenson and Friesen (1969) showed the first evidence that the emotions in facial expressions are universal. Although facial expressions are focused on the relationship of emotions with emotions, it cannot be said that facial expressions convey emotions only. Hence, facial expressions include a number of functions. For example, a person can raise eyebrows if they are curious or interested in a subject. In an established dialogue, it can be conveyed 
that the speech is over or the subject needs to be changed through facial expressions. In cognitive processes including focusing, some changes may occur in facial expression such as eyebrows. Besides, it is possible to use facial expressions in conversation, eating and pronunciation which are integral parts of our life (Matsumoto \& Ekman, 2008).

Some emotions are thought to be more fundamental than others. According to Ekman (2007), there are seven emotions: anger, happiness, sadness, surprise, disgust, fear and contempt. Some researchers suggest that feelings of shame, interest and guilt can also be the basic emotions (Izard, 1977). In a recent study, the views of the scientists working with emotions about basic emotions were taken. According to the results of this study, it was found that the participants were examining the emotions of anger (91\%), fear (90\%), disgust (86\%), sadness $(80 \%)$ and happiness $(76 \%)$ in the basic emotions category (Ekman, 2016).

In many studies, it was supported that emotions in facial expressions were universal (Ekman, Sorenson \& Friesen, 1969; Ekman \& Friesen, 1971; Ekman, 1971). In addition, it is stated that there are studies supporting the fact that more than thirty studies about the recognition of emotions in facial expressions are universal (Matsumoto, 2001). In addition to being universal in the facial expressions, these expressions are also influenced by cultural factors. These factors can be listed as gender (Hampson, van Anders \& Mullin, 2006; Matsumoto, 1992; Merten, 2005), physiological status of the individual (Derntl et al., 2008; Killgore, Balkin, Yarnell ve Capaldi II, 2017), cultural characteristic of the person in the image/photograph (Elfenbein \& Ambady, 2002), personality trait of the participant (Matsumoto et al., 2000).

Emotions in facial expressions can be separated. There are differences such as the occurrence time of the expression of emotion and the level of tension of the muscles in the face. These statements are grouped under four headings: macro expressions, micro expressions, subtle expressions and partial expressions (Matsumoto, Frank \& Hwang, 2013: 37).

Research on emotions in facial expressions has some methodological differences. When the literature is examined, it is seen that two methods are used for muscle movements in the face. The first of these is researches about the participants' own facial expressions; the second one is the research of the facial expressions shown to the participants. In other words, 
the first one is the examination of the muscles in the facial expression by the researcher (encoding); the second is the participant's evaluation of the facial expressions shown to the participants (decoding).

Taken together, while there are many studies on facial expressions in the international literature, there are limited studies on this subject in national literature. This study aims to fill this gap in our country. It is also thought that it will shed light on the researchers who will work on facial expressions.

\section{Kaynakça / References}

Adolphs, R. (2002). Neural systems for recognizing emotion. Current Opinion in Neurobiology, 12(2), 169-177. doi: 10.1016/S09594388(02)00301-X.

Adolphs, R., Tranel, D., Damasio, H., ve Damasio, A. R. (1995). Fear and the human amygdala. Journal of Neuroscience, 15(9), 5879-5891. doi: 10.1523/JNEUROSCI.15-09-05879.1995.

Aichhorn, W. ve Kronberger, H. (2012). The Nature of Emotions. Deuterocanonical and Cognate Literature Yearbook, 2011(1), pp. 515-526. doi:10.1515/dcly.2012.2011.1.515.

Arpita, P. (2012). A comparative study on facial emotion recognition ability and empathy in mental health, medical and non-clinical university students (Order No. 10169148). Available from ProQuest Dissertations ve Theses Global. (1825309150). 4 Haziran 2017 tarihinde https://search.proquest.com/docview/1825309150?accountid=11248 adresinden erişildi.

Bard, K. (2003). Development of emotional expressions in chimpanzees (Pan troglodytes). Emotions inside out: 130 years after Darwin's the expression of the emotions in man and animals içinde. New York Academy of Sciences.

Beck, A. T. (Ed.). (1979). Cognitive therapy of depression. Guilford Press.

Boyatzis, C. J., Chazan, E., ve Ting, C. Z. (1993). Preschool children's decoding of facial emotions. The Journal of Genetic Psychology, 154(3), 375-382. Doi:10.1080/00221325.1993.10532190. 
Burrows, A. M., Waller, B. M., Parr, L. A., ve Bonar, C. J. (2006). Muscles of facial expression in the chimpanzee (Pan troglodytes): descriptive, comparative and phylogenetic contexts. Journal of Anatomy, 208(2), 153-167. Doi:10.1111/j.1469-7580.2006.00523.x.

Camras, L. A., Fatani, S. S., Fraumeni, B. R., ve Shuster, M. M. (2016). The development of facial expressions. Current perspectives on infant emotions. Barrett, L. F., Lewis, M. ve Haviland - Jones, J. M. (Ed.), Handbook of Emotions (4th ed.). (s. 255-271) içinde. Guilford Publications.

Cozolino, L. J. (2014). The neuroscience of human relationships: attachment and the developing social brain. New York: W.W. Norton ve Company.

Darwin, C., Ekman, P., ve Prodger, P. (1998). The expression of the emotions in man and animals. Oxford University Press, USA. (Kitabın orijinal basımı 1872 yılında yapılmıştır).

Derntl, B., Kryspin-Exner, I., Fernbach, E., Moser, E., ve Habel, U. (2008). Emotion recognition accuracy in healthy young females is associated with cycle phase. Hormones and Behavior, 53(1), 90-95. Doi: 10.1016/j.yhbeh.2007.09.006.

Desmond, A., ve Moore, J. (2017). Charles Darwin (E. Kllıç, Çeviren). Türkiye İş Bankası Kültür Yayınları.

Diep, A. K. (2002). The interaction of emotional facial expressions and memory recognition of humans' faces (Order No. 3055137). Available from ProQuest Dissertations and Theses Global. (251455306). 12 Haziran 2017 tarihinde https://search.proquest.com/docview $/ 251455306$ ? accountid $=11248$ adresinden erişildi.

Domico, M. J. (2011). Doctoral-Level Clinical Psychology Students' Ability to Perceive Emotions Through Briefly Presented Facial Expressions at Various Levels of Clinical Experience at Various Levels of Clinical Experience. The Chicago School of Professional Psychology, 109 pages. 4 Haziran 2017 tarihinde http://proquest.umi.com/pqdweb?did$=2219981771$ vesid $=1 \mathrm{veFmt}=2$ veclien $\underline{\mathrm{tId}=1898 \mathrm{veRQT}=309 \mathrm{veVName}=\mathrm{PQD}}$ adresinden erişildi.

Ekman, P. (1971). Universals and cultural differences in facial expressions of emotion. Nebraska Symposium on Motivation içinde. University of Nebraska Press. 
Ekman, P. (2003). Darwin, deception, and facial expression. Annals of the New York Academy of Sciences, 1000(1), 205-221.

Ekman, P. (2007). Emotions revealed: Recognizing faces and feelings to improve communication and emotional life. Macmillan.

Ekman, P. (2016). What Scientists Who Study Emotion Agree About. Perspectives on Psychological Science. Doi: 10.1177/1745691615596992.

Ekman, P., ve Cordaro, D. (2011). What is meant by calling emotions basic. Emotion Review, 3(4), 364-370. Doi: 10.1177/1754073911410740.

Ekman, P., ve Friesen, W. V. (1969). Nonverbal Leakage and Clues to Deception. Psychiatry, 32(1), 88-106. Doi:10.1080/00332747.1969.11023575.

Ekman, P., ve Friesen, W. V. (1971). Constants across cultures in the face and emotion. Journal of Personality and Social Psychology, 17(2), 124129. Doi: $10.1037 / \mathrm{h} 0030377$.

Ekman, P., ve Friesen, W. V. (1976). Pictures of facial affect (POFA). 10 Ocak 2018 tarihinde https://www.paulekman.com/product/pictures-offacial-affect-pofa/ adresinden erişildi.

Ekman, P., ve Friesen, W. V. (1978). Facial Action Coding System: Investigator's Guide. 10 Ocak 2018 tarihinde https://www.paulekman.com/product/facs-manual// adresinden erişildi.

Ekman, P., ve Friesen, W. V. (1983). EMFACS facial coding manual. Human Interaction Laboratory, San Francisco.

Ekman, P., ve Friesen, W. V. (1986). A new pan-cultural facial expression of emotion. Motivation and Emotion, 10(2), 159-168.

Ekman, P., ve Friesen, W. V. (2003). Unmasking the face: A guide to recognizing emotions from facial clues. Ishk.

Ekman, P., ve Rosenberg, E. L. (2005). What the face reveals: Basic and applied studies of spontaneous expression using the Facial Action Coding System (FACS). (2.ed.). Oxford University Press, USA.

Ekman, P., Levenson, R. W., ve Friesen, W. V. (1983). Autonomic nervous system activity distinguishes among emotions. Science, 221(4616), 1208-1210.

Ekman, P., Sorenson, E. R., ve Friesen, W. V. (1969). Pan-cultural elements in facial displays of emotion. Science, 164(3875), 86-88. doi: 10.1126/science.164.3875.86. 
Field, T. M., Woodson, R., Cohen, D., Greenberg, R., Garcia, R., ve Collins, K. (1983). Discrimination and imitation of facial expressions by term and preterm neonates. Infant Behavior and Development, 6(4), 485-489.

Field, T. M., Woodson, R., Cohen, D., Greenberg, R., Garcia, R., ve Collins, K. (1983). Discrimination and imitation of facial expressions by term and preterm neonates. Infant Behavior ve Development.

Freud, S. (1912). The dynamics of transference. Classics in psychoanalytic techniques.

Freud, S. (1920). A general introduction to psychoanalysis. Boni and Liveright. Galati, D., Miceli, R., ve Sini, B. (2001). Judging and coding facial expression of emotions in congenitally blind children. International Journal of Behavioral Development, 25(3), 268-278.

Galati, D., Sini, B., Schmidt, S., ve Tinti, C. (2003). Spontaneous facial expressions in congenitally blind and sighted children aged 8-11. Journal of Visual Impairment and Blindness, 97(7), 418-428.

Goldsmith, H. H. (1994). Parsing the emotional domain from a developmental perspective., Ekman ve Davidson (Ed.) The nature of emotion: Fundamental questions, (s. 68-73) içinde. Oxford University Press.

Greenberg, L. (2006). Emotion-focused therapy: A synopsis. Journal of Contemporary Psychotherapy, 36(2), 87-93.

Greenberg, L. S. (2011). Emotion-focused therapy. American Psychological Association.

Greenberg, L. S. (2015). Emotion - Focused Therapy: Coaching Clients to Work Through Their Feelings. (2.ed.). American Psychological Association.

Greenberg, L. S., ve Safran, J. D. (1989). Emotion in psychotherapy. American Psychologist, 44(1), 19.

Gülbetekin, E., Bayraktar, S., Özkan, Ö., ve Özkan, Ö. (2017). Subjective Recognition of Emotional Expressions in Face Transplant Patients. Journal of Nonverbal Behavior, 41(4), 325-343.

Haggard, E. A., ve Isaacs, K. S. (1966). Micromomentary facial expressions as indicators of ego mechanisms in psychotherapy. Methods of Research in Psychotherapy içinde (s. 154-165). Springer US. doi: 10.1007/978-1-4684-6045-2_14. 
Hall, J. A., ve Matsumoto, D. (2004). Gender differences in judgments of multiple emotions from facial expressions. Emotion, 4(2), 201. Doi:10.1037/1528-3542.4.2.201.

Hampson, E., van Anders, S. M., ve Mullin, L. I. (2006). A female advantage in the recognition of emotional facial expressions: Test of an evolutionary hypothesis. Evolution and Human Behavior, 27(6), 401416. Doi:10.1016/j.evolhumbehav.2006.05.002.

Harper, R. S. (1950). The first psychological laboratory. Isis, 41(2), 158-161. Humintell (2018). https://www.humintell.com/research-news/.

Izard, C. E. (1991). Emotions, personality, and psychotherapy. The psychology of emotions. New York, NY, US.

Izard, C. E. (1994). Innate and universal facial expressions: Evidence from developmental and cross-cultural research. Psychological Bulletin, 115(2), 288-299. doi: 10.1037/0033-2909.115.2.288.

Izard, C. E., Dougherty, L. M., ve Hembree, E. A. (1983). A system for identifying affect expressions by holistic judgments (AFFEX). Instructional Resources Center, University of Delaware.

Izard, C.E., (1979). The Maximally Discriminative Facial Movement Coding System (MAX). University of Delaware, Instructional Resource Center.

Kadak, M. T., Demir, T., ve Doğangün, B. (2013). Otizmde Yüz ve Duyguların Yüz İfadelerini Tanıma. Psikiyatride Güncel Yaklaşımlar, 5(1).

Killgore, W. D., Balkin, T. J., Yarnell, A. M., ve Capaldi II, V. F. (2017). Sleep deprivation impairs recognition of specific emotions. Neurobiology of Sleep and Circadian Rhythms, 3, 10-16.

LaBarbera, J. D., Izard, C. E., Vietze, P., ve Parisi, S. A. (1976). Four-and six-month-old infants' visual responses to joy, anger, and neutral expressions. Child Development, 535-538. 13 Nisan 2017 tarihinde http://www.jstor.org/stable/1128816 adresinden erişildi.

Matsumoto, D. (1992). American-Japanese cultural differences in recognition of universial facial expression. Journal of Cross-Cultural Psychology 23, 72-84. Doi:10.1177/0022022192231005.

Matsumoto, D. (2001). Culture and Emotion. D. Matsumoto (Ed.), The handbook of culture and psychology (pp. 171-194) içinde. New York: Oxford University Press. 
Matsumoto, D., ve Ekman, P. (1988). Japanese and Caucasian facial expressions of emotion (JACFEE). [Fotoğraf seti].

Matsumoto, D., ve Ekman, P. (2008). Facial Expression Analysis Emotion Signaling. Scholarpedia, 1-11. doi:10.4249/scholarpedia.4237.

Matsumoto, D., ve Willingham, B. (2009). Spontaneous Facial Expressions of Emotion of Congenitally and Noncongenitally Blind Individuals. Journal of Personality and Social Psychology, 96(1), 1-10. Doi: 10.1037/a0014037.

Matsumoto, D., Frank, M. G., ve Hwang, H. S. (Eds.). (2013). Nonverbal communication: Science and applications: Science and applications. Sage.

Matsumoto, D., LeRoux, J., Wilson-Cohn, C., Raroque, J., Kooken, K., Ekman, P., ... ve Amo, L. (2000). A new test to measure emotion recognition ability: Matsumoto and Ekman's Japanese and Caucasian Brief Affect Recognition Test (JACBART). Journal of Nonverbal Behavior, 24(3), 179-209. Doi:10.1023/A:1006668120583.

Merten, J. (2005). Culture, gender and the recognition of the basic emotions. Psychologia: An International Journal of Psychology in the Orient, 48, 306-316. Doi:10.2117/psysoc.2005.306.

Paiva-Silva, A. I. D., Pontes, M. K., Aguiar, J. S. R., ve de Souza, W. C. (2016). How do we evaluate facial emotion recognition?. Psychology ve Neuroscience, 9(2), 153. Doi:10.1037/pne0000047.

Panksepp, J. (2004). Affective neuroscience: The foundations of human and animal emotions. Oxford University Press.

Phelps, E. A. (2004). Human emotion and memory: interactions of the amygdala and hippocampal complex. Current Opinion in Neurobiology, 14(2), 198-202.

Phillips, M. L., Drevets, W. C., Rauch, S. L., ve Lane, R. (2003). Neurobiology of emotion perception I: The neural basis of normal emotion perception. Biological Psychiatry, 54(5), 504-514. Doi:10.1016/S00063223(03)00168-9.

Piaget, J. (1964). Part I: Cognitive development in children: Piaget development and learning. Journal of Research in Science Teaching, 2(3), 176-186.

Russell, J., ve Fernandez-Dols, J., M. (1997). The psychology of facial expression. https://doi.org/10.1017/CBO9780511659911. 
Skinner, B. F. (1963). Operant behavior. American Psychologist, 18(8), 503. Sloan, D. M. (2004). Emotion-focused therapy: An interview with Leslie Greenberg. Journal of Contemporary Psychotherapy, 34(2), 105-116.

Snodgrass, S. E. (1992). Further effects of role versus gender on interpersonal sensitivity. Journal of Personality and Social Psychology, 62(1), 154.

Tatar, Z. B., Yargıç, İ., Oflaz, S., ve Büyükgök, P. D. (2015). Erişkin Dikkat Eksikliği Hiperaktivite Bozukluğunda Duygu Tanımanın Dikkat ve Dürtüsellik Belirtileri ile İlişkisi. Türk Psikiyatri Dergisi; 26. 172, 180.

Thompson, A. E., ve Voyer, D. (2014). Sex differences in the ability to recognise non-verbal displays of emotion: A meta-analysis. Cognition and Emotion, 28(7), 1164-1195. Doi: 10.1080/02699931.2013.875889.

Tomkins, S. S. (1962). Affect, Imagery, Consciousness. New York: Springer. Yang, T. T., Menon, V., Eliez, S., Blasey, C., White, C. D., Reid, A. J., ... ve Reiss, A. L. (2002). Amygdalar activation associated with positive and negative facial expressions. Neuroreport, 13(14), 1737-1741.

Zhang, F., ve Parmley, M. (2011). What your best friend sees that I don't see: Comparing female close friends and casual acquaintances on the perception of emotional facial expressions of varying intensities. Personality and Social Psychology Bulletin, 37(1), 28-39. Doi: 10.1177/0146167210388194.

\section{Kaynakça Bilgisi / Citation Information}

Metin. A. (2019). Yüz ifadelerindeki duygular: Derleme çalışması. OPUSUluslararası Toplum Araştırmaları Dergisi , 10(17), 2027-2055. DOI: 10.26466/opus. 514880 